\title{
LA CRÍTICA LITERARIA EN LA PRENSA COLOMBIANA DE LA SEGUNDA MITAD DEL SIGLO XIX: LA DEMOCRACIA (1849-1850) IRIS PERIÓDICO DE SEÑORAS (1866)
}

\author{
Ladys Jiménez \\ Profesora Programa de Lengua Castellana
}

\begin{abstract}
"la independencia había creado de hecho las nuevas nacionalidades; pero al identificarlas les había propuesto el arduo problema de esbozar urgentemente su personalidad peculiar y diseñar el itinerario posible de su futura marcha"

José Luis Díaz Romero
\end{abstract}

\section{A manera de introducción}

La prensa se convierte en elemento esencial de la vida pública y la política, y la literatura se nutre de las polémicas de los periódicos, además es a través de la prensa que comienzan a circular las obras deescritores nacionales e internacionales (sobre todo franceses)en la sociedad urbana y en la que se publican las primeras obras nacionales que comenzaban a trazar un nuevopanorama literario y nacional. Por tanto la prensa es un documento de importante valor histórico, en la medida que permite indagar por la subjetividad de un período y de unos actores sociales dados. "constituye una fuente primaria que no sólo consigna la información sino que la interpreta, la valora, la señala, la exalta o la vitupera; en suma, toma partido frente a los sucesos ocurridos (...) y En tanto que documento sesgado y subjetivo, la prensa refleja los imaginarios de una época, los sentidos comunes y las maneras mediante las cuales se argumenta o contra argumenta sobre los más variados asuntos de la vida nacional..." (Uribe, Álvarez, 2002. p. xii, xiii.)
En el mismo sentido el profesor Bedoya en su artículo "La prensa como objeto de investigación para un estudio histórico de la literatura colombiana"1 afirma que:

La historia de la literatura está unida a la historia de la prensa. Las publicaciones periódicas generales, pero luego y más exactamente las publicaciones periódicas especializadas en lo literario, garantizaron la propia vida de la literatura, ya que en la prensa se funden las prácticas que permiten su existencia, a saber: la producción del escritor, la edición del impresor y la recepción del lector crítico. La prensa es vitrina del escritor, medio material de publicación y evaluadora y jueza de lo literario (incluso al grado de rechazar u opacar obras y artistas). Dado lo anterior, una evaluación histórica de la literatura no debe olvidar el análisis de las revistas, los periódicos, los suplementos y los folletines. (Bedoya, 2011, 92).

Por tanto no podemos desconocer la importancia que tienen las publicaciones periódicas (prensa y revistas) en el origen y desarrollo de la literatura en Hispanoamérica tanto para el siglo XIX ${ }^{2}$ como para el siglo $X X^{3}$, pues gracias a estas muchos autores

1 - Bedoya, Gustavo, "La prensa como objeto de investigación para un estudio histórico de la literatura colombiana. Balance historiográfico y establecimiento del corpus", en: Estudios de Literatura Colombiana. Medellín: Universidad de Antioquia. ISSN: 0124-4812. Número 28, ene.-jun., p. 79-209. en Estudios de Literatura Colombiana, (2011)

2 - Al respecto Raymond Wiliiam en su texto ideología en la novela afirma que la prensa fue imprescindible para el desarrollo de la literatura ya que es a través de ésta se dan a conocer las producciones literarias nacionales e internacionales, La ideología y la novela de los siglos XIX y XX en Colombia, publicado en http://javeriana.edu.co/narrativa_colombiana/contenido/bibliograf/williams/ideoiogiaespanola.htm consultado [08/10/2013]

3 - Para Angel Rama en Medio siglo de literatura 1920-1972 afirma que el desarrollo de Las vanguardias en Hispanoamérica se nuclean en torno a los manifiestos y las revistas, entre las principales destaca "Los Nuevos", Voces (1917), Proa (1922-1923) Martín Fierro (1924-1927). Por su parte, Anderson Imbert, en su texto Historia de la Literatura Hispanoamericana afirma que: "Es difícil estudiar esos "Ismos" porque, al principio decidieron no existir como literatura. Debe estudiárselos en dos pasos. El primero es el de las revistas; el segundo el de los libros" (Imbert, 1982, 72) 
lograron su relevancia en la vida literaria e intelectual. "la historia de la literatura está unida a la historia de la prensa y un estudio histórico de la literatura no debe olvidar el análisis de las revistas, los periódicos, los suplementos y los folletines y debe ser vista como "ente protagonista del devenir histórico" (Bedoya, 2009)

Por estas y otras razones, las publicaciones periódicas, en especial las literarias, son una fuente de estudio invaluable, para comprender ¿por qué se privilegian ciertos géneros discursivos en contraposición a otros?, ¿qué factores intervienen en la canonización de algunos autores, y en la descanonización de otros? y ¿por qué se lee a algunos autores extranjeros y a otros no?, ¿Cuál era la intención de la publicación de los folletines? y ¿Qué relaciones se establecen entre la literatura, lo ideológico, lo cultural y lo social?.

\section{La crítica literaria y el proyecto de Nación}

La actividad literaria en la prensa no solo difundió saberes y promovió imaginarios, sino, que también ayudó a forjar: la idea de nación y el campo literario colombiano. A partir de la publicación de novelasfolletín, crónicas, ensayos, reseñas de libros, avisos de variada índole, traducciones de obras literarias (sobre todo francesas), poesías, cuadros de costumbres, entre otros géneros discursivos se fue configurando una tradición literaria en el país. Un claro ejemplo de ello se evidencia en La Democracia (1849-1853)] y [El Iris periódico de señoras (1866).

En estos periódicos, como otros, de publicación nacional se evidencian dos tendencias: la primera abarca la primera mitad del siglo XIX y se caracteriza por un afán didáctico de tinte iluminista. La segunda se gesta a partir de 1850 en adelante y se caracteriza una prensa más especializada que se vincula al proceso de profesionalización del escritor y del campo cultural / intelectual. Por tanto la autonomía del campo literario en Colombia no arriba sino hacia mediados del siglo XIX, momento en que la literatura "supera"de alguna manera la dependencia directa que tenía con el dominio de lo político y asume un carácter más especializado respecto a otras producciones simbólicas.

Un ejemplo de la primera tendencia es La Democracia de Rafael Núñez- prensa sobre los debates de la actividad política, moral y cívica, que se enuncian en editoriales, reseñas y artículos. Mientras que un ejemplo de la segunda tendencia se expresa en el editorial de El Irisen el que se afirma: "Hay en el país multitud de periódicos destinados a la discusión de cuestiones religiosas, sociales i políticas. El nuestro será un campo, no oscurecido por las pasiones del partido, en donde los amigos de la literatura podrán ensalzar todo lo que es noble i bello. ${ }^{14}$ Junto con este proceso de especialización se aprecia la profesionalización del escritor y la emergencia de un grupo significativo de intelectuales como José María Vergara y Vergara, José Joaquín Borda, Jorge Isaac quienes desarrollarán una corriente identitaria en torno a los valores hispánico católicos.

Bajo este panoramala crítica literaria en la prensa colombiana de la segunda mitad del siglo XIX aporta visiones personales, socialesy estéticas vinculadas a posiciones ideológicas conservadoras de índole religioso que inciden tanto en el imaginario de la identidad nacional como en la conformación del canon literario. En adelante realizaré una aproximación interpretativa de algunos apartes de La democracia (1849), que dirige Rafael Núñez y el periódico de señoras Iris (1866)que dirige José Joaquín Borda ${ }^{6}$ centrándome en las referencias de representación social, en la difusión de un discurso hispano-católico y en la difusión de autores nacionales y extranjeros.

4 - Iris periódico de señoras, año 1, Bogotá 11 de febrero de 1866,pag 1,

5 - Rafael Núñez (Cartagena , 1825 ,

6 - José Joaquín Borda (Boyacá,1835)fué incansable cultivador de las letras y ayudó eficazmente á los jóvenes que mostraban disposiciones para la literatura. Colaboró en muchos periódicos literarios del país y tradujo del francés algunas novelas. Redactó El Hogar con otros distinguidos escritores, Iris con el célebre David Guarín, La Revista de Bogotá con Vergara y Vergara, El Eco Literario, El Album y La Revista Literaria. Fué editor de El Aguinaldo Religioso, Poesías Cubanas, Poesías de Gabriel García Tassara, Cuadros de Costumbres y Descripciones locales de Colombia y de La Lira Colombiana con el mismo Vergara. Publicó dos ediciones de sus Poesías, una traducción de Les Confidencias de Lamartine, una Historia de la Compañía de Jesús en la Nueva Granada, una Historia de Colombia y sus Lecciones de Literatura. Dejó inéditos un Tratado de pronunciación francesa y los dramas Clemencia Lafaille, La Gran artista y La Gran señora y uno de los Mohicanos. Antes de su muerte, acaecida el 29 de Noviembre de 1878 , escribió la composición que se publica adelante, titulada A los que vean mi cadáver.

Tomado de http://www.banrepcultural.org/blaavirtual/literatura/parnacol/jjborda.pdf consultado [07/07/11] 


\section{La democracia 1849-1850: la poesía una ciencia moral}

La Democracia se publico cada diez días, el primer número se publica el primero de abril de $1849 \mathrm{y}$ el último el 5 de diciembre de 1950, en él se publican folletines como El padre Juan, de Eugenio Guinos en los números 1, 2 y 3) Una mujer a los sesenta años, en los números 4 y 5 La Marquesa de Santa Cruz (números 6, 7, 8 y 9) Rosalia, novela italiana en los números 28 y 29). En la sección de variedades se publican artículos como La historia de la Compañía de Jesús en los números 1, 2,3, 4,5,7, 8 y 9, Estudios de la poesía en los números 1 y 3 , El honor y sacrificio, móvil i norma de nuestra conducta social, editado en el número 24 del 16 de mayo de 1850.

En el estudio de la Poesía I el autor sostiene que: "(...) ella nos eleva en alas del éxtasis, a la altura de los hombres esclarecidos cuyos hechos admiramos; despierta en nosotros las ambiciones más nobles; nos hace clementes, filantrópicos, magnánimos, religiosos; nos pone a pensar en lo heroico, en lo grandioso, en lo sublime, hace brillar en nuestra alma la aureola de la inocencia que el aliento de las pasiones había oscurecido i nos dignifica, finalmente, para meditar en Dios" ${ }^{17}$. Alli el autor nos ofrece la exaltación romántica de la moralidad bajo los principios de formación religiosa.

Posteriormente afirma que: "Si: no hay uno solo que haya dejado de experimentar esa sensaciones al recorrer los cantos armoniosos de la Jerusalem restaurada, las comedias de Calderón llenas de filosofía y las dulces églogas de Garcilaso que nos recuerdan la vida primitiva del hombre con toda su sencillez, con toda su inocencia."

Frente a los temas femeninos prevalece una visión cristiana del amor virtuoso: "(...) no querríamos encontrar a la mujer representando a Mesalina; no querríamos distinguir en sus ojos el destello de la voluptuosidad; no querríamos escuchar en sus labios el lenguaje del deleite. Querríamos encontrarla con la irradiación del ángel, hablando de arrullos del riachuelo, velada bajo los pliegues del pudor..$^{19}$

Núñez ubica la poesía en la categoría de las ciencias morales, cree fielmente en su función moral, además afirma que ésta influye en nuestra vida de una manera favorable, "continúa alimentando las tendencias virtuosas del corazón, continúa depurándolo de los miasmas infectos de las malas pasiones.."10 cree firmemente que el papel de la literatura está en la formación moral de los ciudadanos, de ahí la predilección por algunos autores (Lamartine, Virgílio y Chautebrain) y el rechazo de otros como Shiller y Byron, frente a lo anterior afirma que:

"Por eso desechamos Los Bandidos de Schiller, en donde vemos a un hijo asesinando a su padre: desechamos el Caín de Byron, cuya lectura nos horroriza; i desechamos, por último, todas esas obras en que representan a la escena aquellos crímenes singulares de que la humanidad se espanta y cuyas perspectivas repugnantes no es preciso que se reproduzcan i condenen con las vestiduras poéticas para que la sociedad las execre. (...) Contraémonos, solamente, a esa poesía sublime que encontramos en el Paraiso perdido, el Jénio" del cristianismo, las Meditaciones de Lamartine i otros libros semejantes. ${ }^{1{ }^{12}}$

Es de anotar el discurso republicano afirmado por la moralidad cristiana de la época y el influjo de los autores clásicos y los románticos franceses ${ }^{13}$ en la medida que favorecen el imaginario religioso en la formación de buenos ciudadanos.

"¿Despreciar a la poesía que nos pinta la Eneida de Virgilio todo lo sublime del amor filial: que produce en nuestro corazón el noble deseo de llevar, como Eneas, sobre nuestros hombros el cuerpo venerable que nos dio la vida ¡Despreciar a la poesía que nos presenta toda la ternura de un padre en el que demandaba a Aquiles, en el mismo poema, las reliquias ensangrentadas de Héctor!

7- La democracia, No 1 de 1 de abril de 1849

8 - Mesalina tercera esposa del emperador Claudio, fue célebre por su belleza y sus constantes Infidelidades a su esposo, el emperador, con miembros de la nobleza romana, asi como con soldados, actores, Mesalina tuvo gran influencia politica en las decisiones que tomó su marido durante gran parte de su periodo como emperador Romano .

9 - La Democracia 1 de abril de 1849

10 - Ibld.

11 - Genio,

12 - La Democracia 1 de abril de 1849

13 - Jaramiilo Uribe, "la influencia de los románticos franceses y de la revolución de 1848 en el pensamiento político colombiano del siglo XIX" en la Personalidad histórica de Coiombia y otros ensayos, El Ancora Editores, Bogotá 1994 pág. 162-190 
Que nos ofrece en Los Mártires de Chauteuabriand el mas acabado modelo de los amantes llenos de pureza y religión!

Que nos presenta en El Moro Espósito de Saavedra el contraste precioso del falso I verdadero sacerdote! ¡Queréis mejores libros de moral? ¡En dónde los encontraremos útiles, si nos hablan del respeto del hijo, de la ternura del padre, de la pureza de los amantes i de la abnegación del sacerdote? ${ }^{14}$

En el estudio de la poesía II publicado en la sección de variedades del 20 de marzo de 1849 plantea la diferencia entre versificar y poetizar, para esto toma como ejemplos las obras de Gerardo Lobo y Quevedo para afirmar que la versificación es un arte puramente mecánico, y la poesía una ciencia moral:

Las obras de Gerardo Lobo ${ }^{15}$ están medidas cuidadosamente; lo mismo podemos decir de las de Quevedo; isin embargo, ni en aquellas, ni en una gran parte de estas se encuentra la sublimidad poética, cualidad que resalta en las hermosas páginas de Los Cuadros de la naturaleza de Humboldt, La Atala i Los Martires de Chateubriand, El Telémaco de Fenelon, i la Educación de las madres de Aimé Martin, libros en donde el metro no ejerce papel alguno. ${ }^{16}$

Vemos como en esta cita se evidencia por una parte el afán didáctico y moralizante y por otro me atrevería a decir un gesto moderno al poner en cuestión la versificación métrica, que tendrá su esplendor hasta las vanguardias hispanoamericanas.

Más adelante explica cuales son los objetivos de la verdadera ciencia poética:

El poeta tiene dos grandes manantiales para el alimento de sus composiciones: Dios i La naturaleza: la naturaleza moral que es el hombre, la naturaleza física que son los demás objetos de la creación. Tiene a Dios para ofrecerle el incienso de sus inspiraciones, porque es el origen i fundamento del universo i deben bendecirlo, adorarlo i enlazarlo. Porque Dios es el resumen de ese gran todo que contemplamos absortos i cuyas imágenes tratamos de reproducir al son de nuestra lira. Porque nada más augusto, más excelso, más sublime. Porque cada letra de ese nombre sacrosanto envuelve un mundo de pensamientos i de veneración. Porque ninguna inteligencia humana puede detenerse en esa palabra misteriosa sin que sienta bullir en su alma los arrobamientos más profundos, la poesía misma. Después se presenta el hombre con sus pasiones y virtudes. El hombre que en sus buenas y malas inclinaciones revela que una de sus mitades pertenece al cielo i la otra a la tierra.

Finaliza el estudio con las observaciones la naturaleza física: el reino vegetal, con la zoología, el cielo y el mar como fuente de inspiración "Ved joh poetas! El panorama inmenso donde debéis templar vuestra inspirada lira. Dios y sus OBRAS; hé aquí lo que debéis cantar!"17

Observamos enlos dos estudios que la crítica sobre la poesía se funda precisamente en la idea de la utilidad moral, que ayuda a depurar"los miasmas infectos de las malas pasiones" También se evidencia la preferenciade ciertos autores franceses, y con ello los temas que refieren en consonancia con los requerimientos de una élite formada bajo los dogmas de la religión católica.

Los cuadros de costumbres y la idea de naciónlris periódico de señoras Bogotá 1866 El Iris, "Periódico literario dedicado al bello sexo" (Bogotá, 1866-1868), El Iris de Bogotá incluía poesías, muchas veces dedicadas a los álbumes de las señoritas; artículos sobre la caridad cristiana; (...) novelas por entregas y cuadros de costumbres de autores nacionales y extranjeros -entre ellos Víctor Hugo, Julio Arboleda, Soledad Acosta de Samper y muchos firmados con seudónimos o nombres sin apellidos.

En la editorial del periódico José Joaquín Borda expresa que este periódico está dedicado a: "las señoras de nuestro país, le hemos dado el nombre de "Iris" símbolo de la paz, como la mujer lo es de concordia i de amor."18 De igual modo habla de la exclusiva filiación literaria: "Hay en el país multitud de periódicos destinados a la discusión de cuestiones religiosas, sociales i políticas. El nuestro será un campo, no oscurecido por las pasiones del partido,

14 -

15 - Jerardo Lobo

16 - La democracia 20 de marzo de 1849

17 - La democracia 20 de marzo de 1849

18 - |ris periódico de señoras, año 1, Bogotá 11 de febrero de 1866 
en donde los amigos de la literatura podrán ensalzar todo lo que es noble i bello."

Plantea el desconocimiento de los autores nacionales en la república y fuera de ella y la necesidad que estos sean conocidos sobre todo José María Vergara y Vergara y Jorge Isaacs: "Desconocidas están aun las bellezas i producciones de nuestro suelo: desconocido en los vecinos países su progreso científico, literario i artístico: desconocido casi totalmente los grandes hombres que han producido i los hechos de su portentosa historia."

Además agrega que el periódico no solo se dedicará a la literatura nacional, sino, también americana:

"I no aspiramos a fundar un periódico de literatura nacional solamente: sino de literatura americana. ¡Cuántos tesoros poseen las otras repúblicas, desconocidos en nuestro país hasta por los hombres de estudio! Muchos se quedan sumergidos en el océano del periodismo político, i ni las colecciones literarias llegan a nuestras playas, sino en ocasiones especiales. En todo caso nos será satisfactorio contribuir a la comunicación intelectual entre pueblos por tantos vínculos enlazados." ${ }^{119}$

Para José Joaquín Borda la literatura "la literatura es la verdadera expresión de cada sociedad. El literato como el político y el filósofo, necesitan conocer las costumbres del pueblo en que vive, costumbres que son tan variadas como los pueblos, como las clases i condiciones sociales" ${ }^{120}$ El escritor de costumbres: "es un pintor, con la ventaja que se puede copiar no solo los cuerpos, sino también el pensamiento y la palabra. Obra interesante sería aquella que pintase la diversidad de pueblos que moran en la tierra y sus distintas y peculiaridades costumbres!" en este aparte el autor presenta su postura frente a la literatura y los cuadros de costumbres, más adelante realiza una descripción de las distintas razas en el país:

Unos son los hábitos de la raza que extendida desde siglos en las amenazas comarcas de las zonas templadas, ha conquistado la civilización, endulzan-do sus costumbres a merced al cristianismo y al progreso material. Distintos son los de la raza sumergida en los arenales del África o esclavizada en el resto del mundo. Distintos también los de la sencillas raza de indios diseminados en los inmensos imperios de las Indias orientales o en los desiertos de América y Oceanía. (EI Iris, 1866)

Frente al norte expresa una visión de supremacía, caracterizándolas como:

Las"razas vigorosas"y con respecto a los diferentes estados que componen la nación establece diferencias físicas y morales desde un paradigma eurocéntrico: "Los Estados que forman la nación, más que por las leyes políticas están separados por diferencias físicas, así como también por cualidades morales. En unas partes la sangre hierve, siempre en fermentación y domina el espíritu: en otras los hábitos de orden y trabajo, como las fisonomías, revelan el carácter flemático i mesurado, no obstante ser ambos ${ }^{21}$ de la misma raza. Allí domina el bullicio, en las asambleas que dirigen los destinos del pueblo como en las fiestas y diversiones públicas: aquí la moderación y el orden dá un carácter apático aun a los juegos de los niños. (El Iris, 1866)

Y más adelante afirma: "Los usos de la sociedad europea implantados aquí por la raza blanca forman un contraste que salta a la vista, con los de las tribus medio civilizadas que componen la clase baja del pueblo, sobre todos en los campos, i con los de la raza negra condenada a la servidumbre, de la cual en las altas esferas solo empieza a asomar la frente."(EI Iris, 1866)

$Y$ añade entre otras, las siguientes:

Nuestras costumbres, pues, son una mina inagotable para los escritores de este género que encontrarán en ellas temas variados $\mathrm{i}$ altamente interesantes en el orden religioso, como en el orden civil" y que su misión es "altamente moralizadora: a lo menos vale más que no haya literatura, si esta presenta solamente cuadros de inmoralidad o de escándalo. (El Iris, 1866)

A estos escritos toca corregir las malas costumbres (y aún las malas frases) ensalzar los usos dignos de elogio i agradar con esa pintura, que no habla a los ojos sino al alma.

Plantea que:

El estilo de los escritos de costumbres es variado como los asuntos que tocan": pero su principal mérito consiste en la sencillez, la suavidad y la gracia.

¡Cuántos de esos cuadros, sin embargo, se brindarán

19 - lbíd, pág. 1

20 - Ibíd.

21 - En el texto original aparece tildado ámbos 
para lo patético! ¡cuántos para la sátira, más no esa sátira incisiva y envenenada que lleva la muerte al honor, a la dignidad y a la dicha del hombre, sino a la corrección al vicio y al error!

Los asuntos de costumbres se adaptan a la prosa y al verso: la narración y el diálogo son su forma.

Finaliza con una valoración positiva de Vergara y Vergara: "En nuestro país ha habido muy buenos escritores de costumbres, aunque su número no es muy crecido; lo que se debe sin duda a las dificultades que este género de escritos presenta. No basta para esto la facilidad de escribir, ni una vasta erudición: es preciso hallarse dotado de viva imaginación y de un espíritu observador: de otro modo se escribirán disertaciones, muy importantes tal vez; pero no se copiarán costumbres. Excelentes artículos se encuentran diseminados en la multitud de periódicos que entre nosotros imitan al fósforo en su ardor como en la prontitud con que se extinguen. El señor José $M$. Vergara se han propuesto recoger los mejores que se han publicado en el país, y publicarlos en un bello tomo de $\mathbf{4 0 0}$ páginas, del cual han salido ya algunas entregas. El suscribirse a ese libro proporcionará muy agradables ratos y ayudará a realizar una obra digna de nuestra patria." ${ }^{\text {"2 }}$

Lo anterior no es más que una muestra de la idea de nación que dibuja la crítica literaria colombiana: una nación eurocentrica cimentada bajo los dictámenes y la herencia católica, y la función de lo literario se reduce a la función moral y didáctica. La crítica dicta cuales son los autores nacionales e internacionales moralmente aptos para leer como José María Vergara y Vergara. Chautebrain o Virgilio.

Desde las páginas de estos periódicos, a lo largo del siglo, escritores como Nuñez, Isaac, José Joaquín Borda, entre muchos otros, desarrollarán una ensayística en torno a la identidad y la construcción de las naciones republicanas.

La prensa es el principal espacio de publicación para los autores y autoras en el siglo XIX; es a través de ella que comienzan a circular las obras de escritores nacionales e internacionales (ante todo franceses, ingleses $y$, en menor medida, españoles) en la sociedad urbana. Del mismo modo, en ella se publican las primeras obras literarias que comenza- ban a diseñar un nuevo panorama en relación con el campo cultural en Colombia y el concepto de lo literario. Que tal como lo presenta Walter Mignolo es un concepto variable de acuerdo a las relaciones que se establecen con lo moral o lo ideológico.

Digamos que el concepto de literatura, y la familia correspondiente, son conceptos "vacíos" (semejantes a los de $\langle<| 0$ bello $\rangle>,<<\mid 0$ bueno $>$, etc.) donde las ambigüedades son inevitables debido a las propias características del concepto: al ser <<vacíos〉> estos conceptos permite que se los interprete según la conveniencia de los presupuestos ideológicos que rigen el discurso en el que se insertan ${ }^{23}$.

Desde las páginas de la prensa escritores como Rafael Núñez y José Joaquín Borda prescribe lo literario y la función de lo literario, de alguna manera dictan cuales son las costumbres que debe pintar el escritor $^{24}$, como debe escribirla, además dibuja una conciencia nacional que se sustenta bajo ideas colonialistas.

Finalmente, y retomando a Terry Eagletón quien sostiene que: los juicios de valor que constituyen la literatura son históricamente variables y los juicios de valor se relacionan estrechamente con las ideologías sociales ${ }^{25}$,es decir, quelo literario se vincula con las estructuras de poder, y tal como lo afirma Raymond Williams "la crítica literaria y la academia han estado estrechamente ligadas a la oligarquía, (la clase alta, la elite universitaria y la iglesia católica (...) Además ha cumplido una importante función legitimadora: a través de un proceso de exclusión e inclusión (...) ha institucionalizado valores literarios y sobre todo consagrado a sus escritores"En el mismo sentido la profesora Flor María Rodríguez menciona que los críticos del siglo XIX:"(...) ejercieron un proceso de mediación dentro de la progresiva construcción, desarrollo y consolidación de la sociedad, y por tanto, de la literatura; para ellos, el producto literario se convirtió en un arma de crítica social"(Rodríguez, 2006 p, 5)Por lo anterior, se hace realmente necesario una revisión y restructuración del canon literario que se configuró en el XIX ya que éste se hizo a espalda de las particularidades de la realidad nacional y regional,

22 - Iris periódico de señoras, año 1, Bogotá 11 de febrero de 1866

23 - Véase Walter Mignolo, "El concepto de Literatura" en Elementos para una teoría del texto literario, Barcelona, Crítica. (1978) p.28

24 - Obsevamos como José Joaquin Borda priveligla las costumbres de la raza blanca, mientras que los usos de la raza indígena y negra son ridiculizados y puestos en cuestión.

25 - Terry Eagleton¿Qué es Literatura?" en Una introducción a la teoría literaria, EAGLETON, Santafé de Bogotá: FCE, 1994. 
además se encuentra vehiculado a la Arcadia Heleno Católica ${ }^{26}$, que sustenta los valores hispánico - católicos. Un el desafío para investigadores y docentes estaría en la relectura reivindicación de obras y autores que se encuentran al margen del canon y proponen una visón más americanista, menos euro céntrica que tanto violencia simbólica ha generado en los imaginarios sociales y culturales de Colombia.

\section{Bibliografía}

ANDERSON Imbert, Enrique, Historia de la literatura hispanoamericana, 2 vols. México, FCE, 1970. (p.72)

BEDOYA Sánchez, Gustavo Adolfo "La prensa como objeto de investigación para un estudio histórico de la literatura colombiana. Balance historiográfico y establecimiento del corpus", en: Estudios de Literatura Colombiana. Medellín: Universidad de Antioquia. ISSN: 0123-4412. Número 28, ene.jun., p. 89-109. en Estudios de Literatura Colombiana, (2011)

EAGLETON Terry ¿Qué es Literatura?" en Una introducción a la teoría literaria, Santafé de Bogotá: FCE, 1994. MIGNOLO, Walter, Elementos para una teoría del texto literario, Barcelona, Crítica. (1978)

RAMA, Ángel, Novela en América Latina: panoramas: 1920-1980, Procultura, Bogotá 1982

URIBE,Jaramillo, "la influencia de los románticos franceses y de la revolución de 1848 en el pensamiento político colombiano del siglo XIX" en La Personalidad histórica de Colombia y otros ensayos, El Ancora Editores, Bogotá 1994, pág. 162-190

Rodríguez Arenas, Flor María, Bibliografía de la Literatura Colombiana del siglo XIX, Tomo I Stock Cero, Buenos Aires, 2006, pág 5.

WILLIAMS, Raymond L. Novela y poder en Colombia. 1844-1987. Bogotá: Tercer Mundo, 1991.

\section{Periódicos:}

La Democracia Rafael Núnez(1849-1850)

Iris Periódico de señoritas (1866)

\footnotetext{
26 - La Arcadia Heleno Católica Raymond Williams la ubica en el período de 1810-1862 comprende los años de la formación de la república, marcada por la crisis y varias guerras civiles, para Williams "muchas características del antiguo régimen permanecieron sin alteración, ya que prácticamente la clase dirigente seguía en el poder (...) los conservadores defienden el sistema centralista y a menudo se referían con nostalgia a la época colonial, expresando en sus textos literarios el anhelo de un país que pudiera llegar a ser una Arcadia Heleno Católica"Véase más en: "Colombia su historia y sus Regiones" en Novela y Poder en Colombia (1844-1987, (Williams, 1992, p 27-28)
} 




